This is an electronic reprint of the original article. This reprint may differ from the original in pagination and typographic detail.

\author{
Author(s): Haapala, Eero; Eloranta, Aino-Maija; Venäläinen, Taisa; Jalkanen, Henna; Poikkeus, \\ Anna-Maija; Ahonen, Timo; Lindi, Virpi; Lakka, Timo A.
}

Title: $\quad$ Diet quality and academic achievement : A prospective study among primary school children

Year: $\quad 2017$

Version:

Please cite the original version:

Haapala, E., Eloranta, A.-M., Venäläinen, T., Jalkanen, H., Poikkeus, A.-M., Ahonen, T., Lindi, V., \& Lakka, T. A. (2017). Diet quality and academic achievement : A prospective study among primary school children. European Journal of Nutrition, 56(7), 2299-2308. https://doi.org/10.1007/s00394-016-1270-5

All material supplied via JYX is protected by copyright and other intellectual property rights, and duplication or sale of all or part of any of the repository collections is not permitted, except that material may be duplicated by you for your research use or educational purposes in electronic or print form. You must obtain permission for any other use. Electronic or print copies may not be offered, whether for sale or otherwise to anyone who is not an authorised user. 
This is an Author version of the article published in the European Journal of Nutrition 2016. DOI: $10.1007 / \mathrm{s} 00394-016-1270-5$

\section{Diet quality and academic achievement - A prospective study among primary school children}

Eero A. Haapala ${ }^{1,2}$, Aino-Maija Eloranta ${ }^{1}$, Taisa Venäläinen ${ }^{1,3}$, Henna Jalkanen ${ }^{1}$, Anna-Maija Poikkeus ${ }^{4}$, Timo Ahonen ${ }^{5}$, Virpi Lindi ${ }^{1}$, Timo A. Lakka ${ }^{1,6,7}$

Affiliations: ${ }^{1}$ Institute of Biomedicine / Physiology, School of Medicine, University of Eastern Finland, Kuopio, Finland; ${ }^{2}$ Childhoold Health \& Active Living Research Group, Department of Biology of Physical Activity, University of Jyväskylä, Jyväskylä, Finland; ${ }^{3}$ Institute of Public Health and Clinical Nutrition, School of Medicine, University of Eastern Finland, Kuopio, Finland. ${ }^{4}$ Department of Teacher Education, University of Jyväskylä, Jyväskylä, Finland; ${ }^{5}$ Department of Psychology, University of Jyväskylä, Jyväskylä, Finland. ${ }^{6}$ Department of Clinical Physiology and Nuclear Medicine, Kuopio University Hospital and University of Eastern Finland, Kuopio, Finland; ${ }^{7}$ Kuopio Research Institute of Exercise Medicine, Kuopio, Finland

Address correspondence to: Eero A. Haapala, Ph.D., Institute of Biomedicine / Physiology, School of Medicine, University of Eastern Finland, PO Box 1627, FI-70211 Kuopio, Finland,

Short Title: Diet quality and academic achievement

Key Words: Diet quality, diet, children, brain, learning, academic achievement

Funding Sources: Ministry of Social Affairs and Health of Finland, Ministry of Education and Culture of Finland, University of Eastern Finland, Finnish Innovation Fund Sitra, Social Insurance Institution of Finland, Finnish Cultural Foundation, Juho Vainio Foundation, Foundation for Paediatric Research, Paavo Nurmi Foundation, Paulo Foundation, Diabetes Research Foundation, Research Committee of the Kuopio University Hospital Catchment Area (State Research Funding) and Kuopio University Hospital (EVO funding number 5031343), Päivikki and Sakari Sohlberg Foundation, City of Kuopio, Jenny \& Antti Wihuri Foundation

Clinical trial registration: ClinicalTrials.gov Identifier: NCT01803776. 
Purpose: Poor diet quality may impair academic achievement in children, but such evidence is limited. Therefore, we investigated the associations of healthy diet in Grade 1 assessed by Mediterranean Diet Score (MDS), Baltic Sea Diet Score (BSDS), and Finnish Children Healthy Eating Index (FCHEI) with academic achievement in Grades 1-3 in children.

Methods: The participants were 161 Finnish children who were 6-8-year-old in Grade 1 and attended in a large ongoing physical activity and dietary intervention study. Dietary factors were assessed using 4-day food records and MDS, BSDS, and FCHEI were calculated. Academic achievement was assessed by reading fluency, reading comprehension, and arithmetic skill tests. The data were analyzed using linear regression analysis and analysis of covariance adjusted for age, sex, parental education, household income, body fat percentage, physical activity, the PANIC Study group, and total energy intake.

Results: MDS was positively associated with reading comprehension in Grade 3 (standardized regression coefficient $\beta=0.167, P=0.032$ ). BSDS was positively associated with reading fluency in Grades $2-3$ and reading comprehension in Grades $1-3$ ( $\beta=0.161$ to $0.274, P<0.05)$. FCHEI was positively related to reading fluency in Grades 1-2 and reading comprehension in Grades 1-3 ( $\beta=0.190$ to $0.344, P<0.05$ ). Children in the highest third of BSDS and FCHEI had better reading fluency and reading comprehension in Grades $1-3$ than children in the lowest third $(P<0.05)$. None of the diet scores was associated with arithmetic skills.

Conclusions: Healthier diet assessed by BSDS or FCHEI in Grade 1 was associated with better reading skills, but not with arithmetic skills, among children in Grades 1-3. Long-term intervention studies are needed to investigate the effects of improvements in diet quality on academic achievement among children. 


\section{Introduction}

Poor nutrition may impair the rapidly developing brain and cognitive functions and low quality diet may also deteriorate children's academic achievement [1]. Therefore, recent evidence suggesting that children's dietary patterns typically include a high intake of saturated fat and sucrose, a high consumption of fast foods, and a low consumption of vegetables is alarming [2-6]. Poor academic achievement in childhood has been linked to increased risk of adulthood obesity, unemployment, and low socioeconomic positioning in adulthood, suggesting that it is important to identify possibilities to support academic achievement in childhood [7-9].

A few studies suggest that a higher intake of some nutrients, such as iron and polyunsaturated fatty acids, and a lower intake of saturated fatty acids are related to better cognitive functions and academic achievement in children [10-13]. However, improvements in dietary patterns may be more easily translated to real life conditions than those in single nutrients, because single nutrients do not normally exist in isolation and are interrelated and synergistic [14, 15]. Although evidence on the associations of dietary patterns with academic achievement is limited, some studies suggest a direct relationship of adherence to the Mediterranean style diet assessed by the KIDMED index [16, 17], and the Healthy Eating Index [18] with academic achievement in children and adolescents. Moreover, a dietary pattern including a high consumption of sausage, fast food, snacks, and sugar sweetened beverages at the age of three years has been related to poorer academic achievement at the age of 10 years among children [19].

There are differences in food cultures and food choices between geographical regions and populations. Although the Mediterranean style diet has frequently been used to describe healthy diet [15], it may not be easily translated to other countries, such as the Nordic countries. The Baltic Sea Diet Score (BSDS) [20] and the Finnish Children Healthy Eating Index (FCHEI) [21] were developed to illustrate a healthy dietary pattern in the Nordic countries, including Finland. We have previously reported that a lower consumption of vegetables and a higher consumption of red meat and sausage were related to poorer cognition but that poorer overall diet quality assessed by BSDS had the strongest association with worse cognition in children and particularly in boys [22]. However, there are no reports on the associations of BSDS or FCHEI with academic achievement in children.

Due to the increased emphasis on education and learning, evidence on the associations of diet quality with academic achievement among children would provide valuable information for schools and parents to implement actions to support learning and academic achievement. We therefore 
investigated the relationships of diet quality in Grade 1, assessed by the Mediterranean Diet Score (MDS) [23], BSDS, and FCHEI, to academic achievement in Grades 1-3 among Finnish primary school children.

\section{Methods}

\section{Study design and study population}

Data for the present analyses were obtained from the Physical Activity and Nutrition in Children (PANIC) Study [24] and the First Steps Study [25], two independent studies that are being conducted simultaneously in the City of Kuopio, Finland. The PANIC Study is an ongoing controlled family-based and individualized physical activity and dietary intervention study in a population sample of children. We invited 736 children 6-8 years of age who were in Grade 1 in 2007-2009 to participate in the baseline examinations of the study in that timeframe. Of the 736 invited children, 512 (70\%) participated. The First Steps Study is an ongoing follow-up study in a population-based sample of 2000 children from four municipalities in different parts of Finland that was initiated in 2006. Altogether 207 children from the City of Kuopio participated both in the PANIC Study and in the First Steps Study. We obtained data on dietary and confounding factors in Grade 1 from the PANIC Study and data on reading and arithmetic skills in Grades 1-3 from the First Steps Study. Complete data on variables used in the present analyses were available for 161 children ( 87 boys, 74 girls) in Grade 1, for 158 children (86 boys, 72 girls) in Grade 2, and for 152 children ( 83 boys, 69 girls) in Grade 3.

Children who were excluded from the present analyses because of incomplete data were less likely to be at risk for reading disability $(P=0.026)$ and had poorer reading comprehension in Grade 2 $(P=0.002)$, a higher maximal workload in exercise test per lean body mass $(P=0.021)$, and a higher MDS score $(P=0.013)$ than the included children.

The PANIC Study protocol was approved by the Research Ethics Committee of the Hospital District of Northern Savo, Kuopio, and the First Steps Study protocol was approved by the Research Ethics Committee of the University of Jyväskylä. All participating children and their parents provided their written informed consent.

\section{Assessment of maturity and anthropometrics}

All children underwent a clinical examination at baseline of the PANIC Study. A research physician assessed pubertal status using the 5 stage criteria described by Tanner [26]. The boys were defined 
as having entered clinical puberty, if their testicular volume assessed by an orchidometer was $>3 \mathrm{ml}$ (Stage $\geq 2$ ). The girls were defined as having entered clinical puberty if their breast development had started (Stage $\geq 2$ ). Body weight and height were measured using standard protocols described earlier [24]. The prevalence of overweight and obesity was defined using age and sex-specific reference values published by Cole and co-workers [27].

\section{Assessment of dietary factors}

We assessed energy and nutrient intake and food consumption by food records administered by the parents on four predefined consecutive days, including two weekdays and two weekend days (99\%) or three weekdays and one weekend day (1\%) [24]. A clinical nutritionist gave detailed instructions to the parents to record all food and drinks using household or other measures, such as tablespoons, deciliters, and centimeters. The parents were also instructed to ask their children about food eaten outside home. A clinical nutritionist asked about details of menus and recipes of food served at schools and afternoon daycare from the catering company that provided the food for the schools. A clinical nutritionist used all this information and also a picture booklet of portion sizes to complete the missing information with the families at return [28]. Clinical nutritionists analyzed the food records using the Micro Nutrica ${ }^{\circledR}$ dietary analysis software, Version 2.5 (The Social Insurance Institution of Finland), that utilizes Finnish and international data on nutrient composition of foods [29]. We computed MDS, BSDS, and FCHEI as described in Table 1, with higher score indicating better diet quality. We assessed the number of meals per day based on data from the food records. We classified breakfast, lunch, and dinner as meals and all eating and drinking occasions between the meals as snacks. We categorized the children as those who had eaten all meals daily and those who had skipped any of the meals. The Kappa coefficient was $0.134(P=0.004)$ between MDS and BSDS, $0.097(P=0.023)$ between MDS and FCHEI, and $0.224(P<0.001)$ between BSDS and FCHEI, suggesting that these diet quality indices reflect different aspects of healthy diet.

\section{Assessment of academic achievement}

We assessed academic achievement at the spring semester of Grades 1, 2, and 3. Reading fluency was assessed using a group-administered subtest of the nationally normed reading achievement test battery for primary schools called Ala-asteen lukutesti (ALLU) in Finnish [30]. The test score was the number of correct answers, ranging from 0 to 80, during a 2-minute time limit for items that involved identifying the correct word from four phonologically similar alternatives linked to an adjoining picture. 
123 Reading comprehension was assessed using another group-administered subtest of the ALLU

124 battery [30]. After reading a short text, children were asked to answer to 12 multiple-choice

125 questions including facts, causal relationships, interpretations or conclusions drawn from the text.

126 The test score was the number of correct answers, ranging from 0 to 12 , during the 30 -minute test

127 period when children were allowed to refer to the original text.

128

129

130

131

132

133

134

135

136

137

138

139

140

141

142

143

144

145

146

147

148

149

150

151

152

153

Arithmetic skills were assessed using a basic arithmetic test with a set of visually presented addition and subtraction tasks [31]. Children were asked to perform as many calculations as they could. The test score was the number of correct answers, ranging from 0 to 28 , during the 3 -minute time limit.

\section{Assessment of confounding factors}

Physical performance, adiposity, physical activity, and socioeconomic status have been associated with academic achievement in children [32-34]. The parents were asked to report their completed or ongoing educational degrees and household income. The degree of the more educated parent was used in the analyses. Maximal workload in exercise test per lean mass as an indicator of cardiovascular performance [35], 50-meter agility shuttle run test time as a measure of motor performance [36], body fat percentage and lean mass by dual-energy X-ray absorptiometry [37], and physical activity $[38,39]$ were assessed in the PANIC Study as described previously. The risk of reading disability was determined in the First Steps Study using children's scores in the kindergarten-age assessments of letter knowledge, phonemic awareness, and rapid automatized naming, and the parental self-report of reading difficulties [40]. The PANIC study group (intervention vs. control) was used as a covariate, because the physical activity and dietary intervention in the PANIC Study started before the assessments of academic achievement in the First Steps Study.

\section{Statistical methods}

We performed all data analyses using the SPSS Statistics, Version 21.0 (IBM Corp., Armonk, NY, USA). We compared basic characteristics between boys and girls using the Student's t-test and the Chi Square-test. We investigated the associations of MDS, BSDS, and FCHEI in Grade 1 with reading fluency, reading comprehension, and arithmetic skills in Grades 1-3 using linear regression analysis by forcing MDS, BSDS, or FCHEI with age, sex, parental education, household income, body fat percentage, physical activity, the PANIC Study group, and total energy intake into the models. We also adjusted the data on the associations of MDI, BSDS, or FCHEI with reading and arithmetic skills in Grades 2-3 for the corresponding academic skill in Grade 1. Furthermore, we 
154

155

156

157

158

159

160

161

162

163

164

165

166

167

168

169

170

171

172

173

174

175

176

177

178

179

180

181

182

183

184

185

compared reading fluency, reading comprehension, and arithmetic skills in Grades 1-3 among children in the thirds of MDI, BSDS, or FCHEI in Grade 1 using Repeated Measures Analysis of Covariance. The data were adjusted for age, sex, parental education, household income, body fat percentage, physical activity, the PANIC Study group, and total energy intake and Sidak correction for multiple comparisons. All data were additionally adjusted for clinical puberty, maximal workload in exercise test, 50-meter agility shuttle run test time, the risk of reading disability, or skipping meals. We investigated the effect modification of sex using General Linear Models by analyzing the association of sex*dietary quality index interactions with academic achievement scores. We performed all analyses by combining data on boys and girls because of a limited statistical power to analyze these associations separately in boys and girls and because sex did not modify the associations of diet quality with academic achievement $(P$ for interaction $>0.05$ for all models).

\section{Results}

\section{Characteristics}

The characteristics of the study sample are presented in Table 2. There were no differences in MDS, BSDS, or FCHEI between boys and girls. The boys had poorer reading fluency in Grades 1 and 3, and poorer reading comprehension in Grade 2 than the girls (data not shown).

Associations of MDS, BSDS, and FCHEI with academic achievement

MDS was associated with reading comprehension in Grade 3 after adjustment for age, sex, parental education, household income, body fat percentage, physical activity, the PANIC study group, and total energy intake (Table 3). A higher BSDS was related to better reading fluency in Grades 2-3 and reading comprehension in Grades 1-3 after adjustment for age, sex, parental education, household income, body fat percentage, physical activity, the PANIC study group, and total energy intake. A higher FCHEI was associated with better reading fluency in Grades 1-2 and reading comprehension in Grades 1-3 after adjustment for age, sex, parental education, household income, body fat percentage, physical activity, the PANIC study group, and total energy intake. The relationship of BSDS to reading fluency in Grade 3 and the association of FCHEI with reading fluency in Grade 2 were no longer statistically significant after further adjustment for reading fluency in Grade 1, but the association of BSDS with reading fluency in Grade 2 and with reading comprehension in Grades 2-3, the association of FCHEI with reading comprehension in Grades 23, and the association between MDS and reading comprehension in Grade 3 remained statistically significant after further adjustment for corresponding reading skills in Grade 1 (data not shown). 
Additional adjustment for clinical puberty, maximal workload in exercise test, 50-meter agility shuttle run test time, the risk of reading disability, or skipping meals had no effect on these associations (data not shown).

\section{Differences in academic achievement among children in thirds of MDI, BSDS, and FCHEI}

Children in the highest third of BSDS had consistently better reading fluency (mean difference across Grades $=3.860 ; 95 \% \mathrm{CI}=0.089$ to $7.631, P=0.043)$ and reading comprehension (mean difference across Grades $=1.284 ; 95 \% \mathrm{CI}=0.200$ to $2.368, P=0.015)$ in Grades $1-3$ than children in the lowest third after adjustment for age, sex, parental education, household income, body fat percentage, physical activity, the PANIC study group, and total energy intake. Children in the highest third of BSDS also had better reading comprehension in Grades 1-3 than children in the middle third (mean difference across Grades $=1.086 ; 95 \% \mathrm{CI}=0.054$ to $2.119, P=0.036$ ).

Similarly, children in the highest third of FCHEI had consistently higher reading fluency (mean difference across Grades $1-3=3.912 ; 95 \% \mathrm{CI}=0.027$ to $7.796, P=0.048)$ and reading comprehension (mean difference across Grades $1-3=1.894 ; 95 \% \mathrm{CI}=0.806$ to $2.981, P<0.001$ ) in Grades 1-3 than children in the lowest third after adjustment for age, sex, parental education, household income, and body fat percentage, physical activity, the PANIC study group, and total energy intake. Moreover, children in the middle third of FCHEI had better reading comprehension in Grades $1-3$ than children in the lowest third (mean difference across Grades $1-3=1.034,95 \%$ CI $=0.049$ to $2.018, P=0.036)$. Additional adjustments had no effect on these differences. There were no other differences in academic skills among children in thirds of MDI, BSDS, or FCHEI.

\section{Discussion}

We found that better diet quality in Grade 1 assessed by BSDS and FCHEI was associated with better reading skills among Finnish children. We also observed that children in the highest third of BSDS and FCHEI had better reading skills through Grades 1-3 than children in the lowest third. Moreover, our results provide some evidence that better diet quality is associated with better reading skills in Grades 2-3 independent of reading skills in Grade 1.

Previous studies have shown that a better diet quality is associated with better grade point averages and academic achievement reported by teachers in children and adolescents [16-18, 41]. Moreover, dietary patterns characterized by a high consumption of vegetables, fruit, berries, fish, and nuts in childhood and adolescence have been related to better cognitive functions and academic achievement in later years in some follow-up studies $[19,42]$. We found that better diet quality, assessed by BSDS and FCHEI, was associated with better reading skills but not arithmetic skills. 
218 These observations are supported by the results of the study of Sørensen and coworkers [43] in which a 3 month intervention aimed to improving the quality of school meals improved reading skills, but not arithmetic skills, in children 10 years of age. Our study with the study by Sørensen and coworkers [43] are one of the first studies that have used standardized tests to assess specific academic skills, such as reading and arithmetic skills, instead of overall grade point averages or academic achievement reported by teachers. Taken together, the results of cross-sectional studies and few prospective studies along with our observations suggest that better diet quality may improve academic achievement, and particularly reading skills, during childhood and adolescence. The reason why better diet quality has been linked to better reading skills but not arithmetic skills is currently unknown. One reason for these observations may be that reading requires more complex cognitive functions than basic arithmetic calculations and therefore unhealthy diet may be more strongly related to reading skills than arithmetic skills in children. Nevertheless, more studies on the specific effects of improved diet quality on reading and arithmetic skills in children are needed.

Although BSDS and FCHEI were positively associated with academic achievement, we found only weak associations between MDS and academic achievement. This observation is in contrast to the results of some earlier studies $[16,17]$. One reason for these findings may be that the specific diet identify healthy diet related to academic achievement in our population with specific food choices and culture than diet quality indices developed for other populations and geographical regions. For example, BSDS and FCHEI emphasize the intake of polyunsaturated fatty acids and the consumption low-fat milk whereas MDS gives emphasis to the ratio of monounsaturated to saturated fatty acids and low consumption of milk. Milk is commonly fortified with vitamin D in Finland, and it is the major dietary source of vitamin D among Finnish children [44]. Accordingly, there is some evidence that polyunsaturated fatty acids and vitamin D support normal brain and cognitive development in children $[45,46]$. Another possible explanation for our findings is that the median-based scoring in the MDS may not adequately classify children according to their diet quality and may not cause the required variation in the score. Stricter adherence to the Mediterranean style diet, assessed by the KIDMED index, has been related to better academic achievement among children $[16,17]$. However, we were unable to calculate the KIDMED index in this study, because we used 4-day food records to assess dietary factors in children.

Stricter adherence to the Baltic Sea type diet has been linked to a higher intake of vitamins, polyphenols, flavonoids, and dietary fiber and a lower intake of saturated fatty acids in adults [20]. A higher FCHEI has been associated with a higher intake of vitamin E, vitamin D, polyunsaturated 
251 fatty acids, and dietary fiber and a lower intake of saturated fatty acids in children [21]. These 252 nutrients may enhance synaptic plasticity [47, 48], protect the brain from neuronal damage, support 253 cell proliferation [47], and improve the prerequisites for academic achievement, such as working 254 memory and inhibition $[12,13,49]$. There is also some preliminary evidence that a better breakfast 255 quality is associated with improved working memory, attention, and behavior in children [50, 51]. 256 Thus, better overall diet quality may improve cognitive prerequisites of learning and behavior 257 during school day over a long period of time and thereby enhance learning and academic 258 achievement in children. Furthermore, we found that skipping meals had no effect on the observed 259 associations between diet quality and academic achievement among children.

260 The strengths of the present study include the rigorous methods used to assess dietary factors by 4261 day food records and academic achievement by standardized reading and arithmetic tests, and the 262 prospective study design. We also had the opportunity to control the data for a number of 263 confounding factors. The weaknesses of our study are that we could not draw a conclusion about 264 the causality of the associations. Moreover, we had a relatively small study sample although the 265 children quite well represented the original PANIC Study and the First Step Study populations. The 266 children also came from families with relatively high parental education, and therefore these 267 findings need to be confirmed among children with a lower socioeconomic background. 268 Furthermore, there were some differences in characteristics between the study sample and the 269 excluded children which may slightly decrease the generalizability of our results

270 All children entering public schools in Finland are eligible for free school-lunch that is prepared 271 according to the Finnish dietary recommendations [52]. Thus, all Finnish school-aged children receive at least one healthy meal a day that includes vegetables, low-fat milk, and high-fiber grain products. A healthy school lunch may attenuate the association of diet quality with academic achievement, because it decreases differences in diet quality among children with different socioeconomic backgrounds. Thus, the associations between diet quality and academic achievement may be even stronger in other countries in which healthy meals are not provided by schools.

277 A higher BSDS and FCHEI were associated with better reading skills among children in their first three school years. These results suggest that following the Nordic and Finnish dietary guidelines [52] that results in increased consumption of vegetables, fruit, berries, and low-fat milk and decreased consumption of red meat, sausage, and foods high in sucrose could improve reading skills in school-aged children. Our results provide one of the first evidence on the longitudinal 
associations of diet quality with academic achievement in children and can be used in planning interventions aimed at increasing academic performance in children.

\section{Financial support}

Ministry of Social Affairs and Health of Finland, Ministry of Education and Culture of Finland, University of Eastern Finland, Finnish Innovation Fund Sitra, Social Insurance Institution of Finland, Finnish Cultural Foundation, Juho Vainio Foundation, Foundation for Paediatric Research, Paavo Nurmi Foundation, Paulo Foundation, Diabetes Research Foundation, Research Committee of the Kuopio University Hospital Catchment Area (State Research Funding) and Kuopio University Hospital (EVO funding number 5031343), Päivikki and Sakari Sohlberg Foundation, City of Kuopio, Jenny and Antti Wihuri Foundation.

\section{Conflicts of interest}

On behalf of all authors, the corresponding author states that there is no conflict of interest.

\section{Authorship}

EAH, AME, AMP, VL, and TAL designed the research; AME, TV, VL, AMP, TA, and TAL conducted the research; EAH analyzed the data; EAH, AME, TV, AMP, TA, HJ, VL, and TAL wrote the manuscript; EAH, AME, and TAL had primary responsibility for the final content of the manuscript; All authors read and approved the final version of the manuscript.

\section{References}

1. Nyaradi A, Li J, Hickling S, Foster J, Oddy WH (2013) The role of nutrition in children's neurocognitive development, from pregnancy through childhood. Front Hum Neurosci 7:97.

2. Sijtsma FP, Meyer KA, Steffen LM, Shikany JM, Van Horn L, Harnack L, Kromhout D, Jacobs DR Jr. (2012) Longitudinal trends in diet and effects of sex, race, and education on dietary quality score change: the Coronary Artery Risk Development in Young Adults study. Am J Clin Nutr 95:580-586.

3. Cheng G, Libuda L, Karaolis-Danckert N, Alexy U, Bolzenius K, Remer T, Buyken AE (2010) Trends in dietary carbohydrate quality during puberty from 1988 to 2007: a cause for concern? Br J Nutr 104:1375-1383.

4. Bauer KW, Larson NI, Nelson MC, Story M, Neumark-Sztainer D (2009) Fast food intake among adolescents: secular and longitudinal trends from 1999 to 2004. Prev Med 48:284- 
287.

5. Eloranta A-M, Lindi V, Schwab U, Kiiskinen S, Kalinkin M, Lakka HM, Lakka TA (2011) Dietary factors and their associations with socioeconomic background in Finnish girls and boys 6-8 years of age: the PANIC Study. Eur J Clin Nutr 65:1211-1218.

6. Larson NI, Neumark-Sztainer D, Hannan PJ, Story M (2007) Trends in adolescent fruit and vegetable consumption, 1999-2004: project EAT. Am J Prev Med 32:147-50.

7. Alatupa S, Pulkki-Råback L, Hintsanen M, Ravaja N, Raitakari OT, Telama R, Viikari JS, Keltinkangas-Järvinen L (2010) School performance as a predictor of adulthood obesity: a 21-year follow-up study. Eur J Epidemiol 25:267-274.

8. Kokko K, Pulkkinen L (2000) Aggression in childhood and long-term unemployment in adulthood: A cycle of maladaptation and some protective factors. Dev Psychol 36:463-472.

9. Alatupa S, Pulkki-Råback L, Hintsanen M, Elovainio M, Mullola S, Keltinkangas-Järvinen L (2013) Disruptive behavior in childhood and socioeconomic position in adulthood: a prospective study over 27 years. Int J Public Health 58:247-256.

10. Falkingham M, Abdelhamid A, Curtis P, Fairweather-Tait S, Dye L, Hooper L (2010) The effects of oral iron supplementation on cognition in older children and adults: a systematic review and meta-analysis. Nutr J 9:4.

11. Jiao J, Li Q, Chu J, Zeng W, Yang M, Zhu S (2014) Effect of n-3 PUFA supplementation on cognitive function throughout the life span from infancy to old age: a systematic review and meta-analysis of randomized controlled trials. Am J Clin Nutr J Clin Nutr 100:1422-1436.

12. Baym CL, Khan NA, Monti JM, Raine LB, Drollette ES, Moore RD, Scudder MR, Kramer AF, Hillman CH, Cohen NJ (2014) Dietary lipids are differentially associated with hippocampal-dependent relational memory in prepubescent children. Am J Clin Nutr 99:1026-1032.

13. Zhang J, Hebert J, Muldoon M (2005) Dietary fat intake is associated with psychosocial and cognitive functioning of school-aged children in the United States. J Nutr 135:1967-1973.

14. Tangney CC, Scarmeas N (2012) The good, bad, and ugly? How blood nutrient concentrations may reflect cognitive performance. Neurology 78:230-231.

15. Allès B, Samieri C, Féart C, Jutand MA, Laurin D, Barberger-Gateau P (2012) Dietary patterns: a novel approach to examine the link between nutrition and cognitive function in older individuals. Nutr Res Rev 25:207-222. 
16. Vassiloudis I, Yiannakouris N, Panaqiotakos DB, Apostolopoulos K, Costarelli V (2014) Academic performance in relation to adherence to the Mediterranean diet and energy balance behaviors in Greek primary schoolchildren. J Nutr Educ Behav 46:164-170.

17. Esteban-Cornejo I, Izquierdo-Gomez R, Gómez-Martínez S, Padilla-Moledo C, CastroPinero J, Marcos A, Veiga OL (2016) Adherence to the Mediterranean diet and academic performance in youth: the UP\&DOWN study. Eur J Nutr 55:1133-1140.

18. Florence M, Asbridge M, Veugelers P (2008) Diet quality and academic performance. J Sch Health 78:239-241.

19. Feinstein L, Sabates R, Sorhaindo A, Rogers I, Herrick D, Northstone K, Emmett P (2008) Dietary patterns related to attainment in school: the importance of early eating patterns. $\mathrm{J}$ Epidemiol Community Health 62:734-739.

20. Kanerva N, Kaartinen NE, Schwab U, Lahti-Koski M, Männistö S (2014) The Baltic Sea Diet Score: a tool for assessing healthy eating in Nordic countries. Public Health Nutr 17:1697-1705.

21. Kyttälä P, Erkkola M, Lehtinen-Jacks, S Ovaskainen M, Uusitalo L, Veijola R, Simell O, Knip M, Virtanen SM (2014) Finnish Children Healthy Eating Index (FCHEI) and its associations with family and child characteristics in pre-school children. Public Health Nutr 17:2519-2527.

22. Haapala EA, Eloranta A-M, Venäläinen T, Schwab U, Lindi V, Lakka TA (2015) Associations of diet quality with cognition in children - The Physical Activity and Nutrition in Children Study. Br J Nutr 114:1080-1087.

23. Trichopoulou A, Costacou T, Bamia C, Trichopoulos D (2003) Adherence to a Mediterranean diet and survival in a Greek population. N Engl J Med 348:2599-2608.

24. Eloranta A-M, Lindi V, Schwab U, Tompuri T, Kiiskinen S, Lakka HM, Laitinen T, Lakka TA (2012) Dietary factors associated with overweight and body adiposity in Finnish children aged 6-8 years: the PANIC Study. Int J Obes 36:950-955.

25. Nurmi J-E, Kiuru N, Lerkkanen M-K, Niemi P, Poikkeus A-M, Ahonen T, Leskinen E, Lyyra A-L (2013) Teachers adapt their instruction in reading according to individual children's literacy skills. Learn Individ Differ 23:72-79.

26. Tanner J (1962) Growth at adolescence. Blackwell, Oxford

27. Cole T, Bellizzi M, Flegal K, Dietz W (2000) Establishing a standard definition for child 
overweight and obesity worldwide: international survey. Br Med J 320:1240-1243.

28. Picture book of food portion sizes. The National Public Health Institute, Helsinki, Finland

29. Rastas M, Seppänen R, Knuts L, Hakala P, Karttila V (1997) Nutrient Composition of Foods. The Social Insurance Institution, Helsinki, Finland

30. Lindeman J (1998) ALLU-ala-asteen lukutesti (standardized reading test for comprehensive school). Center for Learning Research. University of Turku, Turku

31. Räsänen P, Aunola K (2007) Test of arithmetics. Test material developed in the First Steps follow-up. University of Jyväskylä, Jyväskylä

32. Haapala EA (2013) Cardiorespiratory fitness and motor skills in relation to cognition and academic performance in children - a review. J Hum Kinet 36:55-68.

33. Reinert KRS, Po'e EK, Barkin SL (2013) The relationship between executive function and obesity in children and adolescents: a systematic literature review. J Obes 2013:820956.

34. Sirin SR (2005) Socioeconomic status and academic achievement: A meta-analytic review of research. Rev Educ Res 75:417-453.

35. Lintu N, Tompuri T, Viitasalo A, Soininen S, Laitinen T, Savonen K, Lindi V, Lakka TA (2014) Cardiovascular fitness and haemodynamic responses to maximal cycle ergometer exercise test in children $6-8$ years of age. J Sports Sci 32:652-659.

36. European Council (1988) EUROFIT: handbook for the EUROFIT tests of physical fitness. Council of Europe, Rome.

37. Tompuri TT, Lakka TA, Hakulinen M, Lindi V, Laaksonen DE, Kilpeläinen TO, Jääskeläinen J, Lakka HM, Laitinen T (2015) Assessment of body composition by dualenergy X-ray absorptiometry, bioimpedance analysis and anthropometrics in children: the Physical Activity and Nutrition in Children study. Clin Physiol Funct Imaging 35:21-33.

38. Väistö J, Eloranta A-M, Viitasalo A, Tompuri T, Lintu N, Karjalainen P, Lapminen EK, Ågren J, Laaksonen DE, Lakka HM, Lindi V, Lakka TA (2014) Physical activity and sedentary behaviour in relation to cardiometabolic risk in children: cross-sectional findings from the Physical Activity and Nutrition in Children (PANIC) Study. Int J Behav Nutr Phys Act 11:55.

39. Haapala EA, Poikkeus A-M, Kukkonen-Harjula K, Tompuri T, Lintu N, Väistö J, Leppänen PH, Laaksonen DE, Lindi V, Lakka TA (2014) Associations of physical activity and sedentary behavior with academic skills - a follow-up study among primary school children. 
PLoS One 10:e107031.

40. Kiuru N, Aunola K, Torppa M, Lerkkanen MK, Poikkeus AM, Niemi P, Viljaranta J, Lyyra AL, Leskinen E, Tolvanen A, Nurmi JE (2012) The role of parenting styles and teacher interactional styles in children's reading and spelling development. J Sch Psychol 50:799823.

41. Sigfúsdóttir ID, Kristjánsson AL, Allegrante JP (2007) Health behaviour and academic achievement in Icelandic school children. Health Educ Res 22:70-80.

42. Nyaradi A, Foster JK, Hickling S, Li J, Ambrosini GL, Jacques A, Oddy WH (2014) Prospective associations between dietary patterns and cognitive performance during adolescence. J Child Psychol Psychiatry 55:1017-1024.

43. Sørensen LB, Dyssegaard CB, Damsgaard CT, Petersen RA, Dalskov SM, Hjorth MF, Andersen R, Tetens I, Ritz C, Astrup A, Lauritzen L, Michaelsen KF, Egelund N (2015) The effects of Nordic school meals on concentration and school performance in 8- to 11-year-old children in the OPUS School Meal Study: a cluster-randomised, controlled, cross-over trial. Br J Nutr 113:1280-1291.

44. Soininen S, Eloranta AM, Lindi V, Venäläinen T, Zaproudina N, Mahonen A, Lakka TA (2016) Determinants of serum 25-hydroxyvitamin D concentration in Finnish children: the Physical Activity and Nutrition in Children (PANIC) study. Br J Nutr 115;1080-1091.

45. Bazinet RP, Layé S (2014) Polyunsaturated fatty acids and their metabolites in brain function and disease. Nat Rev Neurosci 15:771-785.

46. Eyles DW, Burne THJ, McGrath JJ (2013) Vitamin D, effects on brain development, adult brain function and the links between low levels of vitamin D and neuropsychiatric disease. Front Neuroendocrinol 34:47-64.

47. Frisardi V, Panza F, Seripa D, Imbimbo BP, Vendemiale G, Pilotto A, Solfrizzi V (2010) Nutraceutical properties of Mediterranean diet and cognitive decline: possible underlying mechanisms. J Alzheimer's Dis 22:715-740.

48. Wu A, Ying Z, Gomez-Pinilla F (2004) The interplay between oxidative stress and brainderived neurotrophic factor modulates the outcome of a saturated fat diet on synaptic plasticity and cognition. Eur J Neurosci 19:1699-707.

49. Khan NA, Raine LB, Drollette ES, Scudder MR, Kramer AF, Hillman CH (2015) Dietary fiber is positively associated with cognitive control among prepubertal children. J Nutr 
145:143-149.

436 50. Adolphus K, Lawton CL, Dye L (2013) The effects of breakfast on behavior and academic 437 performance in children and adolescents. Front Hum Neurosci 7:425.

438

51. Young H, Benton D (2014) The effect of using isomaltulose (Palatinose ${ }^{\mathrm{TM}}$ ) to modulate the 440 glycaemic properties of breakfast on the cognitive performance of children. Eur J Nutr 54:1013-1020.

52. National Institute of Health and Welfare (2016) Finnish dietary recommendations for families with children. National Nutrition Council, Juvenes Print - Suomen yliopistopaino, Tampere, Finland.

444

445

446

447

448

449

450

451

452

453

454

455

456

457 
461 Figure 1. Differences in reading fluency, reading comprehension, and arithmetic skills in Grades 14623 among 152 children (83 boys, 69 girls) in the thirds of the Baltic Sea Diet Score and Finnish 463 Healthy Eating Index in Grade 1 adjusted for age, sex, parental education, household income, body 464 fat percentage, physical activity, the PANIC study group, and total energy intake. The data are 465 presented as estimated marginal means and their $95 \%$ confidence intervals.
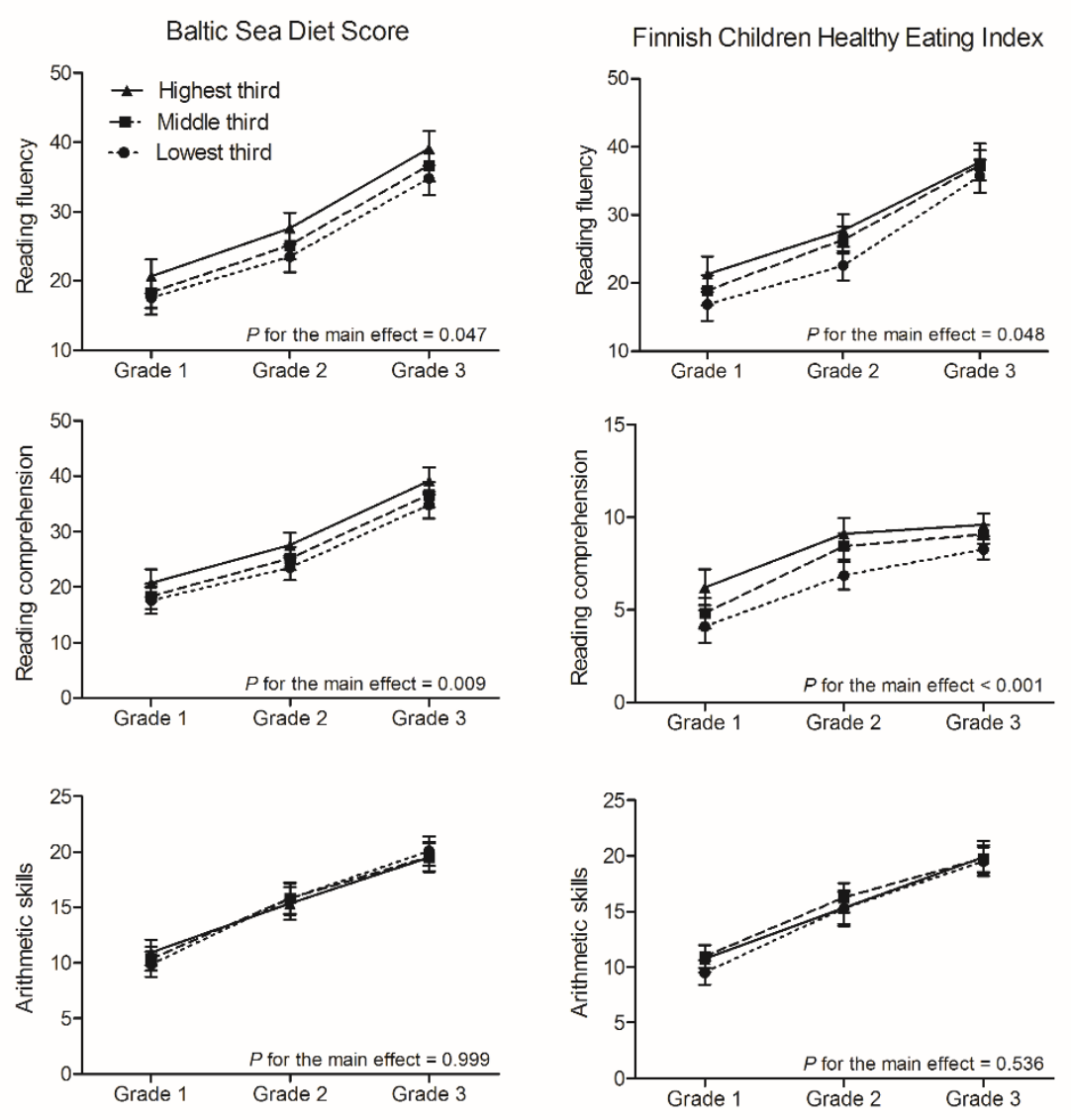
Table 1. Construction of the diet quality indices in the present study

\begin{tabular}{|c|c|c|}
\hline & Components & Scoring \\
\hline \multirow[t]{8}{*}{ Mediterranean Diet Score (MDS) } & Vegetables, g/d & $>$ sex-specific median $=1$, else $=0$ \\
\hline & Fruit, nuts and legumes, g/d & $>$ sex-specific median $=1$, else $=0$ \\
\hline & Grain products, g/d & $>$ sex-specific median $=1$, else $=0$ \\
\hline & Fish, g/d & $>$ sex-specific median $=1$, else $=0$ \\
\hline & Red meat and sausage, g/d & $<$ sex-specific median $=1$, else $=0$ \\
\hline & Poultry, g/d & $<$ sex-specific median $=1$, else $=0$ \\
\hline & Dairy products, g/d & $<$ sex-specific median $=1$, else $=0$ \\
\hline & $\begin{array}{l}\text { Ratio of monounsaturated to saturated } \\
\text { fatty acids }\end{array}$ & $>$ sex-specific median $=1$, else $=0$ \\
\hline \multirow[t]{8}{*}{ Baltic Sea Diet Score (BSDS) } & Fruit and berries, g/d & Quartile 1=0, Quartile 2=1, Quartile 3=2, Quartile 4=3 \\
\hline & Vegetables and legumes, g/d & Quartile 1=0, Quartile 2=1, Quartile 3=2, Quartile 4=3 \\
\hline & High-fiber $(\geq 5 \%)$ grain products, $g / d$ & Quartile 1=0, Quartile 2=1, Quartile 3=2, Quartile 4=3 \\
\hline & Low-fat $(<1 \%)$ milk, g/d & Quartile 1=0, Quartile 2=1, Quartile 3=2, Quartile 4=3 \\
\hline & Fish, g/d & Quartile 1=0, Quartile 2=1, Quartile 3=2, Quartile 4=3 \\
\hline & Red meat and sausage, g/d & Quartile 1=3, Quartile 2=2, Quartile 3=1, Quartile 4=0 \\
\hline & $\begin{array}{l}\text { Ratio of polyunsaturated to saturated } \\
\text { fatty acids }\end{array}$ & Quartile 1=0, Quartile 2=1, Quartile 3=2, Quartile 4=3 \\
\hline & Total fat intake, E\% & Quartile 1=3, Quartile 2=2, Quartile 3=1, Quartile 4=0 \\
\hline \multirow[t]{9}{*}{$\begin{array}{l}\text { Finnish Children Healthy Eating } \\
\text { Index (FCHEI) }\end{array}$} & Vegetables, fruit and berries, $\mathrm{g} / \mathrm{d}$ & $\begin{array}{l}\text { Decile } 1=1 \text {, Decile } 2=2 \text {, Decile } 3=3 \text {, Decile } 4=4 \text {, Decile } 5=5 \text {, } \\
\text { Decile 6=6, Decile 7=7, Decile } 8=8 \text {, Decile 9=9, Decile } 10=10\end{array}$ \\
\hline & Vegetables, fruit and berries, g/d & $\begin{array}{l}\text { Decile } 1=1 \text {, Decile } 2=2 \text {, Decile } 3=3 \text {, Decile } 4=4 \text {, Decile } 5=5 \text {, } \\
\text { Decile } 6=6 \text {, Decile } 7=7 \text {, Decile } 8=8 \text {, Decile } 9=9 \text {, Decile } 10=10\end{array}$ \\
\hline & $\begin{array}{l}\text { Vegetable oils and vegetable-oil-based } \\
\text { margarine }\end{array}$ & $\begin{array}{l}\text { Non-consumers }=0 \text {, Decile } 1=1 \text {, Decile } 2=2 \text {, Decile } 3=3 \text {, Decile } \\
4=4 \text {, }\end{array}$ \\
\hline & (fat $\geq 60 \%$ ), g/day & Decile 5=5, Decile 6=6, Decile 7=7, Decile $8=8$, Decile 9=9, \\
\hline & & Decile \\
\hline & & $10=10$ \\
\hline & $\begin{array}{l}\text { Foods containing high amounts of } \\
\text { sugar } \S\end{array}$ & $\begin{array}{l}\text { Decile } 1=10 \text {, Decile } 2=9 \text {, Decile } 3=8 \text {, Decile } 4=7 \text {, Decile } 5=6 \text {, } \\
\text { Decile } 6=5 \text {, Decile } 7=4 \text {, Decile } 8=3 \text {, Decile } 9=2 \text {, Decile } 10=1\end{array}$ \\
\hline & Fish, g/d & $\begin{array}{l}\text { Non-consumers }=0 \text {, Decile } 5=1 \text {, Decile } 6=2 \text {, Decile } 7=3 \text {, Decile } \\
8=4 \text {, Decile } 9=5 \text {, Decile } 10=6\end{array}$ \\
\hline & Low-fat $(<1 \%)$ milk, g/d & $\begin{array}{l}\text { Non-consumers }=0 \text {, Decile } 2=1 \text {, Decile } 3=2 \text { Decile } 4=3 \text {, Decile } \\
5=4 \text {, Decile } 6=5 \text {, Decile } 7=6 \text {, Decile } 8=7 \text {, Decile } 9=8 \text {, Decile } \\
10=9\end{array}$ \\
\hline
\end{tabular}

$\S$ Including sugar-sweetened beverages, fruit juice, added sugar, chocolate, sweets, pastries, biscuits, ice cream and puddings. 
Table 2. Basic characteristics

\begin{tabular}{|c|c|}
\hline & All children $(\mathrm{N}=161)$ \\
\hline Age (years) & $7.7(0.3)$ \\
\hline Boys/girls $(\mathrm{N})$ & $87 / 74$ \\
\hline Body height $(\mathrm{cm})$ & $129.3(5.4)$ \\
\hline Body weight (kg) & $27.4(5 \cdot 4)$ \\
\hline Body fat percentage & $18.4(11.6)$ \\
\hline Prevalence of overweight and obesity (\%) & 16 \\
\hline Clinical puberty $(\%)$ & 4 \\
\hline \multicolumn{2}{|l|}{ Parental education $(\%)$} \\
\hline Vocational school or less & 19 \\
\hline Polytechnic & 39 \\
\hline University degree & 43 \\
\hline \multicolumn{2}{|l|}{ Household income (\%) } \\
\hline$\leq 30000 €$ & 19 \\
\hline $30001-60000 €$ & 45 \\
\hline$>60000 €$ & 36 \\
\hline Children in the PANIC Study intervention group (\%) & 65 \\
\hline Children with the risk of reading disabilities $(\%)$ & 15 \\
\hline \multicolumn{2}{|l|}{ Physical activity and physical performance } \\
\hline Physical activity $(\mathrm{min} / \mathrm{d})$ & $106.9(39.2)$ \\
\hline Maximal workload per lean body mass (watts/lean mass) & $3.6(0.5)$ \\
\hline Time in 50-meter shuttle run test (seconds) & $24.0(2.1)$ \\
\hline \multicolumn{2}{|l|}{ Dietary factors } \\
\hline Total energy intake (kcal/d) & $1641(300)$ \\
\hline Skipping meals $(\%)$ & 66 \\
\hline Mediterranean Diet Score & $3.8(1.4)$ \\
\hline Baltic Sea Diet Score & $11.4(4.2)$ \\
\hline Finnish Children Healthy Eating Index & $22.9(6.5)$ \\
\hline \multicolumn{2}{|l|}{ Academic achievement in Grade 1} \\
\hline Reading fluency & $18.8(8.9)$ \\
\hline Reading comprehension & $4.9(3.3)$ \\
\hline Arithmetic skills & $10.3(4.0)$ \\
\hline \multicolumn{2}{|l|}{ Academic achievement in Grade 2} \\
\hline Reading fluency & $25.3(8.0)$ \\
\hline Reading comprehension & $9.0(4.0)$ \\
\hline Arithmetic skills & $15.6(5.1)$ \\
\hline \multicolumn{2}{|l|}{ Academic achievement in Grade 3} \\
\hline Reading fluency & $36.8(8.7)$ \\
\hline Reading comprehension & $8.9(2.1)$ \\
\hline Arithmetic skills & $19.6(4.7)$ \\
\hline
\end{tabular}

Data are means (SDs) or percentages (\%). Percentages are rounded and therefore they may account less or more than $100 \% . \mathrm{N}=161$ (87 boys, 74 girls) in Grade 1; N=158 (86 boys, 72 girls) in Grade 2; N=152 ( 83 boys, 69 girls) in Grade 3 
Table 3. Association of the Mediterranean Diet Score, Baltic Sea Diet Score and the Finnish Children Healthy Eating Index with academic achievement in children

\begin{tabular}{|c|c|c|c|c|c|c|}
\hline & \multicolumn{2}{|l|}{ Reading fluency } & \multicolumn{2}{|c|}{ Reading comprehension } & \multicolumn{2}{|l|}{ Arithmetic skills } \\
\hline & $\beta(95 \% \mathrm{CI})$ & $P$ & $\beta(95 \% \mathrm{CI})$ & $P$ & $\beta(95 \% \mathrm{CI})$ & $P$ \\
\hline \multicolumn{7}{|c|}{ Grade 1} \\
\hline Mediterranean Diet Score & $-0.031(-0.182$ to 0.121$)$ & 0.692 & $0.006(-0.150$ to 0.163$)$ & 0.937 & $0.096(-0.059$ to 0.251$)$ & 0.224 \\
\hline Baltic Sea Diet Score & $0.142(-0.012$ to 0.297$)$ & 0.071 & $0.161(0.002$ to 0.320$)$ & 0.047 & $0.139(-0.020$ to 0.298$)$ & 0.086 \\
\hline Finnish Children Healthy Eating Index & $0.190(0.037$ to 0.344$)$ & 0.015 & $0.239(0.083$ to 0.395$)$ & 0.003 & $0.095(-0.065$ to 0.255$)$ & 0.241 \\
\hline \multicolumn{7}{|c|}{ Grade 2} \\
\hline Mediterranean Diet Score & $0.080(-0.077$ to 0.237$)$ & 0.317 & $0.125(-0.033$ to 0.283$)$ & 0.119 & $0.004(-0.155$ to 0.164$)$ & 0.957 \\
\hline Baltic Sea Diet Score & $0.223(0.065$ to 0.381$)$ & 0.006 & $0.274(0.116$ to 0.432$)$ & 0.001 & $0.050(-0.114$ to 0.214$)$ & 0.548 \\
\hline Finnish Children Healthy Eating Index & $0.234(0.073$ to 0.395$)$ & 0.005 & $0.344(0.187$ to 0.501$)$ & $<0.001$ & $0.064(-0.103$ to 0.230$)$ & 0.453 \\
\hline \multicolumn{7}{|c|}{ Grade 3} \\
\hline Mediterranean Diet Score & $0.043(-0.118$ to 0.205$)$ & 0.597 & $0.167(0.015$ to 0.319$)$ & 0.032 & $-0.043(-0.205$ to 0.119$)$ & 0.600 \\
\hline Baltic Sea Diet Score & $0.199(0.035$ to 0.362$)$ & 0.035 & $0.263(0.110$ to 0.416$)$ & 0.001 & $0.000(-0.168$ to 0.167$)$ & 0.996 \\
\hline Finnish Children Healthy Eating Index & $0.113(-0.056$ to 0.281$)$ & 0.188 & $0.272(0.117$ to 0.427$)$ & 0.001 & $0.037(-0.133$ to 0.207$)$ & 0.669 \\
\hline
\end{tabular}

Data are and standardized regression coefficients $(\beta)$ and their $95 \%$ confidence intervals (CI) from linear regression models adjusted for age, sex, parental education, household income, and body fat percentage, physical activity, the PANIC study group, and total energy intake. N=161 (87 boys, 74 girls) in Grade 1; N=158 (86 boys, 72 girls) in Grade 2; N=152 (83 boys, 69 girls) in Grade 3. 